Possibly, gas might do as well, but it is not so handy. In support of these views, I was able to collect 4161 cases of anæsthesia by bromide of ethyl, published by various authors, in which some unsuccessful cases were noted, but not one single death. Can we say the same for choloroform? $I$ have given it 252 times, without ever seeing the least disagreeable symptom. It should be given by what is called the intensive method Up to fifteen years of age ten grammes (two and a half drachms) are sufficient; above that age, a double dose can be used.

With regard to the method of operating, I am opposed to cauterizing, the electric curette of Rousseaux, forceps, the cold snare (Chiari); and limit myself to Gottstein's curette, which answers best of all. At the same time, I am accustomed, after finishing with tho curette, to use the finger for scraping away any small granulations which may have escaped the cutting surface. In this way I am also able to satisfy myself as to the complete success of the operation. A warm nasal douche of boracic acid is then given, to act both as an antiseptic and hæmostatic. This method of orerating only requires a few minutes, and in all my cases I never had the slightest accident. Until complete cicatrization, proved by repeated examinations, had taken place, I ordered boracic glycerine to be used several times in the twenty-four hours.

The prognosis is good. Nasal obstruction disappears. The healing of suppurating otitis, unless there is extensive caries, is hastened. In deafness without suppuration one nearly always obtains rapid recorery of the hearing. In adults, however, secondary lesions of the tympanum and ossicles may remain unchanged. Even in deaf mutes, when young and when their condition is consequent on adenoid vegetations, one may have good results. Frequently in the complications of reflex origin unexpected and brilliant results may be obtained.

Conclusions.-(1) In Italy this disease is fairly frequent. (2) The chief causes are heredity and general affections. (3) The operation should be completed in one sitting, employing Gottstein's curette followed by the finger. (4) Bromide of ethyl is the best anæsthetic for this operation. (5) Auricular affections are in great part due to adenoid vegetations, both during the period of development of the latter and during their retrogression. (6) In all cases where adenoid tumours have been diagnosed there should be no delay in their removal. (7) Before children are admitted into asylums for the deaf and dumb or similar institutions, they should first be submitted to the examination of a specialist, particularly with regard to the affection under discussion.

St. Clair Thomson (Trans.).

\title{
THE STATISTICS OF DISEASES OF THE EAR.
}

By Dr. Hemax (Warsaw).

Real before the Fifth International Congress of Otology, Florence, 1895.

Founderg on his clinical material in the hospital during the last seven years, which was made up of 2808 in-patients, 2203 polyclinic patients, 
3387 men examined with regard to their eligibility for military service, and 268 deaf mutes, Dr. Heiman has arrived at the following statistical results :-

1. The frequency of ear diseases in soldiers; that is to say, between the ages of twenty-one and twenty-six years.

2. The mortality which these diseases occasion at that age.

3. The frequency of diseases in the different segments of the ear.

4. The therapeutical results.

Before enlarging on these different points, he makes the remark that he derives his classification chiefly from the hospital patients, and he considers this material is the most valuable for statistical purposes, for the patients of this class remain longer under observation and treatment, so that definite results may be obtained, while the polyclinic patients and those examined for other purposes have only a relative value from a statistical point of view.

A special table shows these relations very readily. The percentage of aural in-patients in proportion to the general number of patients in hospital $(74,681)$ was $3 \cdot 77$ per cent. The total of all ear patients was 8.74 per cent. of all the hospital patients in general. The ear patients were derived from a body of men averaging from year to year 150,060, the proportion out of these being therefore 0.82 per cent. Dr. Heiman draws from his figures the conclusion that the opinions of Tröltsch and Bürkner, with regard to the frequency of the different diseased and functional changes of the organ of hearing, can have only a theoretical value, and that in a practical sense we have much fewer ear patients, as all the conditions of which these authors spoke, where the patient is little or not at all disturbed, cannot be looked upon as disease.

The mortality of all ear diseases amounted to $0.46 \mathrm{per}$ cent., and the mortality among hospital in-patients to 1.38 per cent. The ratio of mortality in ear cases to the mortality in the hospital in general (2187), equal to 2.92 per cent., was 1.98 per cent. The mortality in diseases of the middle ear amounted to 1.50 per cent., in catarrhal and purulent middle-ear diseases 1.78 per cent., in purulent middle-ear diseases 2.19 per cent., in acute purulent median otitis 0.74 per cent., in chronic middle-ear suppurations $3 \cdot 29$ per cent., and, lastly, in acute middle-ear catarrh 1.43 per cent. Death was occasioned four times by cerebral abscess, three times by cerebellar abscess, sixteen times by meningitis, and sixteen times by sinus thrombosis and septico-pyæmia. (Three cases of pyæmia were cured.) Dr. Heiman is of opinion that the mortality numbers $(0.3$ to 0.5$)$ are far too low, and that we can only determine the actual ratio when we confine ourselves to hospital in-patients. The mortality, according to Sch wartze, is 4.74 per cent.; according to Barker, 2.5 per cent.; according to Bezold, $2 \cdot 15$ per cent. If the limit, according to Heiman, amounts to 1.38 per cent., it is to be explained by the limit of age of the patients, as also by the fact that among his patients there were found many who are ordinarily treated in a polyclinic. This last circumstance supplies, according to Dr. Heiman, an important factor in the determination of the mortality. The frequency of the different forms of ear diseases is set forth in a special table. From the totals of this table, it is found that 
